\title{
The Potential of Iodine Lactoglycerol as an Alternative Fungal Stain in the Laboratory
}

\author{
Lilis Puspa Friliansari*, Erick Khristian, Shofie Agustina Hermawanti \\ Department of Medical Laboratory Technology, School of Health Sciences Jenderal Achmad Yani Cimahi. \\ Jl. Terusan Jend. Sudirman, Baros, Kec. Cimahi Tengah, Kota Cimahi, Jawa Barat 40633, Indonesia
}

\section{ARTICLE INFO}

ABSTRACT

Article History:

Received: December, 2019

Revise: June, 2020

Accepted: July, 2020

Keywords: fungi stain; iodine; lactoglycerol; color intensity
Fungi are eukaryotic and opportunistic organisms that can cause damage and disease. Fungi can be identified by direct staining. The composition of the dyes used in fungi staining are toxic, mutagenic and harmful to laboratory personnel and the environment. Consequently, it is necessary to consider use fungi dye continuously, so its need alternative safety dyes to identify fungi in the laboratory. This research aims to determine the potential of iodine lactoglycerol with different concentrations $(1.25 \%, 2.5 \%$, and $5 \%)$ as an alternative dye for fungi in the laboratory. The research method used experimental design. The samples originate from moldy bread and made 27 of microscopic slides. The microscopic slides were observed with objective 40x magnification. The parameters assessed in this study were the structure and morphology of fungi including hyphae, conidiophores, vesicles, sterigmata and conidiospores and color intensity using the image analysis of ImageJ. The results showed that various concentrations of iodine lactoglycerol can staining the structure and morphology of the fungi properly and clearly. The value of color intensity of each concentration measured has a different average. The highest average value of color intensity concentration was $5 \%$ and the lowest was $1.25 \%$. However, the result of ANOVA test showed a significance of $0.380(\mathrm{P}>0.05)$, which means that is no difference significantly from three of various concentrations. The result showed that the difference concentration of iodine lactoglycerol does not affect the color intensity. The conclusion of this study was iodine lactoglycerol solution can be used as an alternative dye or Lactophenol-cotton Blue (LPCB) substitute for fungi identification. It is recommendation for further research be carried out regarding the decrease in the concentration of alternative color solutions below $1.25 \%$, the incubation time for the preparation of the preparations, and the color stability of the prepared mushroom preparations.

\footnotetext{
*Corresponding author:

Lilis Puspa Friliansari

Department of Medical Laboratory Technology, School of Health Sciences Jenderal Achmad Yani Cimahi Email: lilispuspafriliansari@gmail.com
} 


\section{INTRODUCTION}

Fungi are one of the causes of infectious diseases, especially in tropical countries. Indonesia is a tropical country with high humidity, so mushrooms can be found almost everywhere (Adiguna, 2001). Fungal infections that attack humans are called mycosis. Mycosis is caused by opportunistic and pathogenic fungi, including Dermatophytes sp., Candida sp., Aspergillus sp., Cryptococcus sp., and so on (Kazemi, 2013).

Fungi can be identified in various ways, including direct staining of microscopic slide, fungi culture, immunological reactions, biopsy or histopathological, and examination with wood light. There are various methods of direct preparation staining that can be used to identify fungi, including Periodic Acid Schiff (PAS), KOH, Calcoflour White Stain, Methenamine Silver Stain and Lactophenol-cotton Blue (LPCB) staining (Tille, 2013). Lactophenol-cotton Blue (LPCB) dye is the most commonly method for staining and observing fungi. The using of LPCB to stain the fungi allows samples to be easily microscopic visualized (Vignesh, 2013). The composition of LPCB are crystal cotton blue which functions to stain the fungi, lactic acid to clear the background and sharpen the structure of the fungi, glycerol functions to maintain cell physiology and protect against dryness and phenol crystals to kill the fungi (Himedia, 2019).Phenol as an essential component in LPCB staining is mutagenic and tumorigenic and also very corrosive and poisonous. Phenols are harmful to laboratory personnel and the environment (IPCS, 2018).

Vignesh (2013) mention that iodine glycerol can be used as an alternative for LPCB staining in the identification of fungi. The use of iodine glycerol showed clearer and more detailed fungal morphological than LPCB staining. The glycerol functions as a hygroscopic agent, so that the fungsi slide colored with these alternative dye can be semi-permanent and can be stored for a longer period of time. Lugol iodine is a fungicide that allows it to replace phenol which kills fungi (Russel, 2003).
Iodine is a compound that can be used in staining. Iodine has a relatively much cheaper than LPCB. The price of LPCB which is relatively expensive and contains carcinogenic and mutagenic properties needs to be considered continuously in the laboratory (Santana, et al, 2018). Therefore it is necessary to have other safer alternatives dye in the use of substances especially iodine with different concentrations which impact on morphological and color intensity for identification the fungi in the laboratory.

\section{MATERIALS AND METHODS}

The research method is experimental design. The sample used is mold that grows on the surface of bread. This research used iodine lactoglycerol concentrations of $1.25 \%, 2.5 \%$ and $5 \%$ with wet preparation technique. The test parameters assessed in this study were the structure and morphology of fungi including hyphae, conidiophores, vesicles, sterigmata and conidiospores and the intensity of color that could be absorbed by the fungus by digital analysis. Digital analysis using by the Image-J software.

\section{Population and Sample}

The population in this study were Aspergillus sp. that grows on the surface of the moldy bread. Sampling point taken at random and different positions. The number of repetitions for each sample follows the following formula (Sujarwani, 2015):

$$
\begin{array}{ll}
(\mathrm{n}-1) \times(\mathrm{t}-1) & \geq 15 \\
(\mathrm{n}-1) \times(3-1) & \geq 15 \\
(\mathrm{n}-1) \times 2 & \geq 15 \\
\mathrm{n}-1 & \geq 7.5 \\
\mathrm{n} & \geq 7.5+1 \\
\mathrm{n} & \geq 8.5 \\
\mathrm{n} & \approx 9 \ldots \ldots \ldots(1)
\end{array}
$$

\section{Research Procedure \\ Preparation of $10 \%$ iodine solution}

Ten grams of potassium Iodide (KI) dissolved in $80 \mathrm{ml}$ distilled water, then stir until blended. The solution is put into a $100 \mathrm{~mL}$ volumetric flask and then distilled water is added 
until it reaches the limit mark. The solution is homogenized. After the solution is homogeneous, put the solution into a dark glass bottle.

\section{Dilution of iodine solution}

The 10\% iodine solution was diluted to a concentration (C) of $5 \%$ and $2.5 \%$ as much as 50 $\mathrm{ml}(\mathrm{V})$ with the following calculations:

$\mathrm{V}_{1} \times \mathrm{C}_{1}=\mathrm{V}_{2} \times \mathrm{C}_{2}$

\section{Preparation of $0.25 \%$ lactoglycerol solution}

The technical glycerol is piped as much as $0.25 \mathrm{~mL}$ then put into a $100 \mathrm{ml}$ volumetric flask, add $99.75 \mathrm{ml}$ of lactic acid into the volumetric flask and homogenize.

\section{Making an alternative dye solution)}

Alternative dyes are made at a concentration of $5 \%, 2.5 \%$ and $1.5 \%$ by mixing various concentrations of Iodine solution with lactoglycerol at the same ratio, namely $15 \mathrm{ml}$ of iodine and $15 \mathrm{ml}$ of lactoglycerol (Vignesh, 2013 and Basava, et., al 2016 ).

\section{Preparation and inspection of mushroom wet preparations}

The fungi in the sample were sampled using a skewer and then placed on a clean object glass. The sample is added with 1 drop of alternative dye. Place the cover glass near the sample in an oblique position, then slowly lower the object glass until it covers the entire surface of the sample, lest bubbles form. Wet preparations were observed using a microscope with an objective 40x magnification (Himedia, 2019).

\section{Color Intensity Measurement}

The measurement of color intensity is done with image-J software. Image-J is a software capable of analyzing colors to produce Optical Density (OD) values. Optical Density in this research shows that iodine lactoglycerol is bound to mushroom components.

\section{Procedure for using Image-J for Windows 32 bit}

1. Image-J software is opened and the image is prepared to be analyzed digitally.
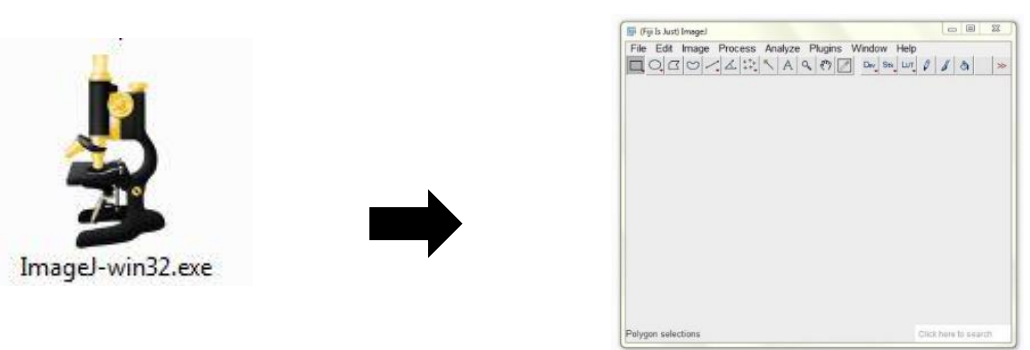

2. In the image-J display, click "File" then click "Open" or press ctrl + O, after that select the image to be analyzed.
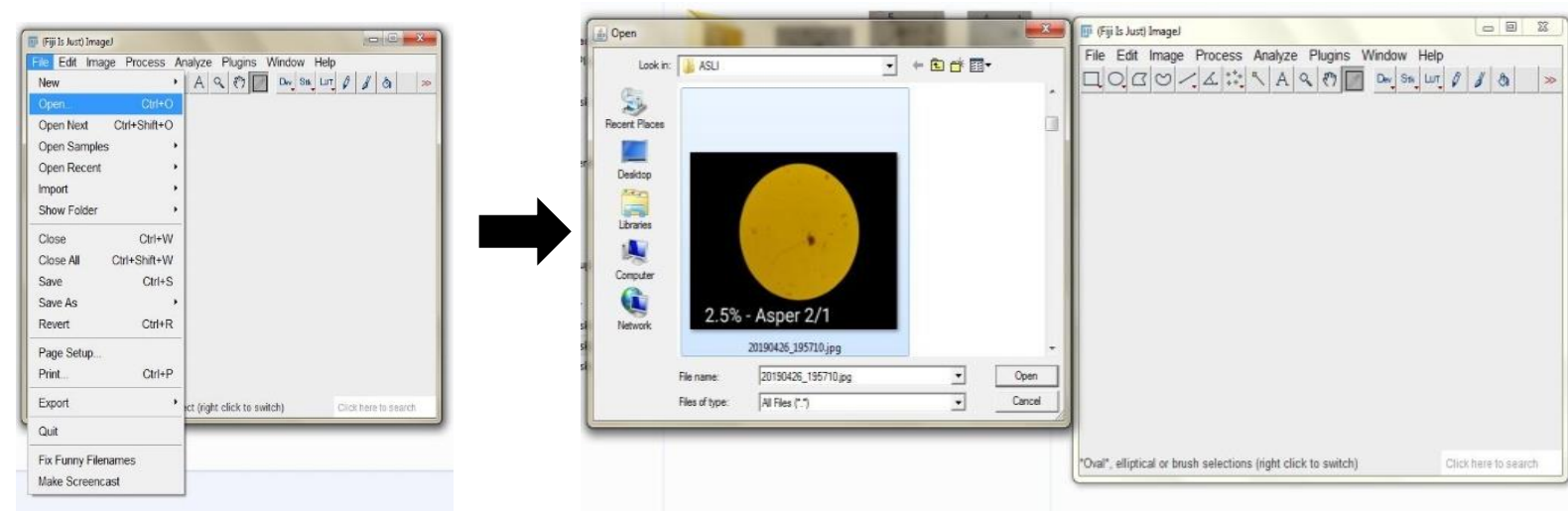
3. The object to be analyzed is selected then click "Edit" after that select "Clear Outside" according to the area to be analyzed.
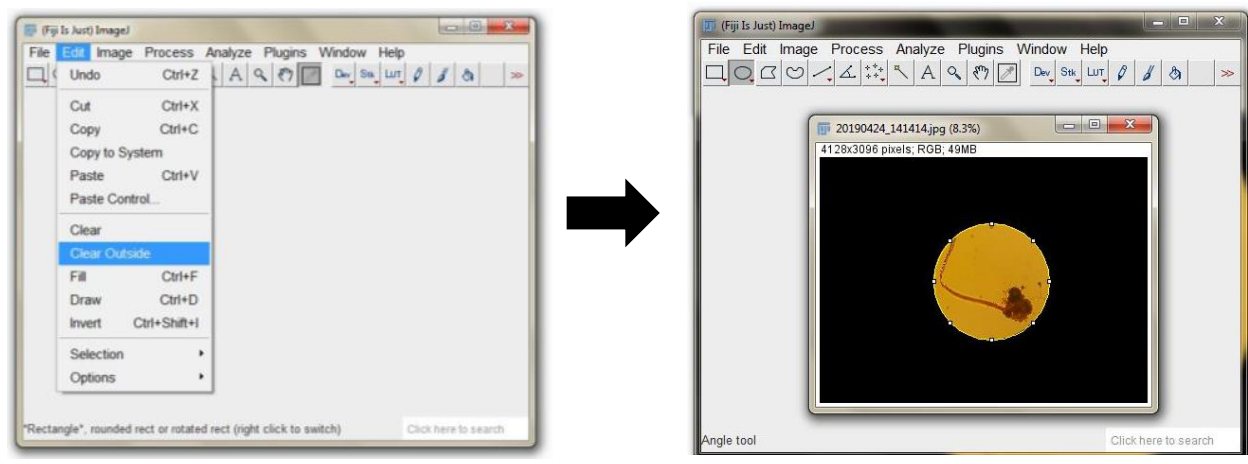

4. Then the image is made on a gray scale by clicking "Image" then clicking "Type" and selecting 8-Bit.
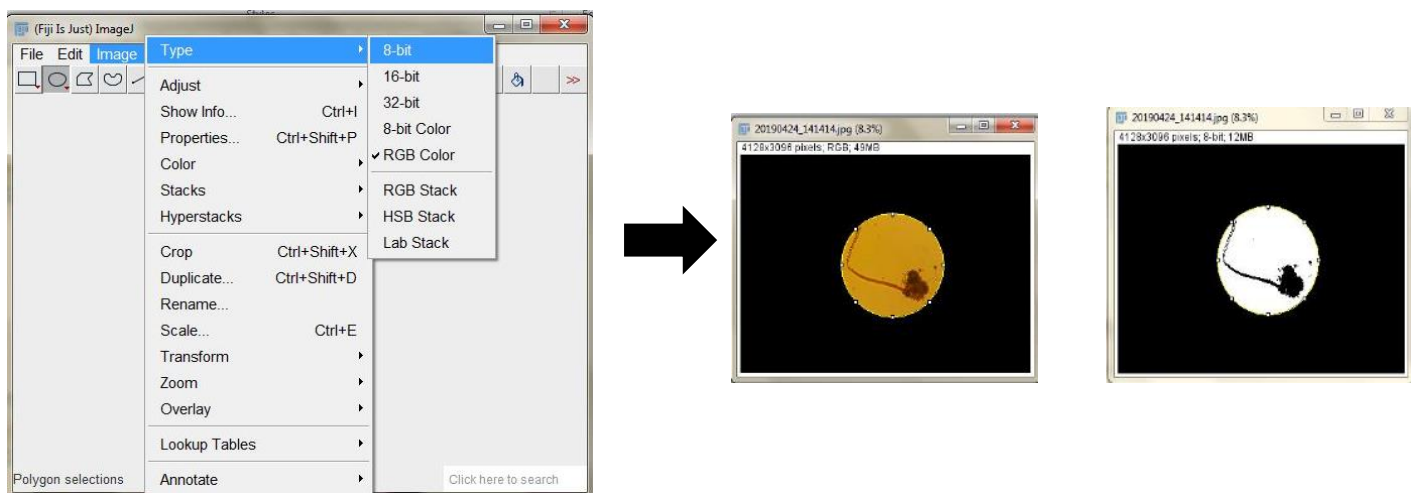

5. After the gray scale image is clicked on the "Image" menu, click on "Adjust" then select "Treshold" then click "Apply".

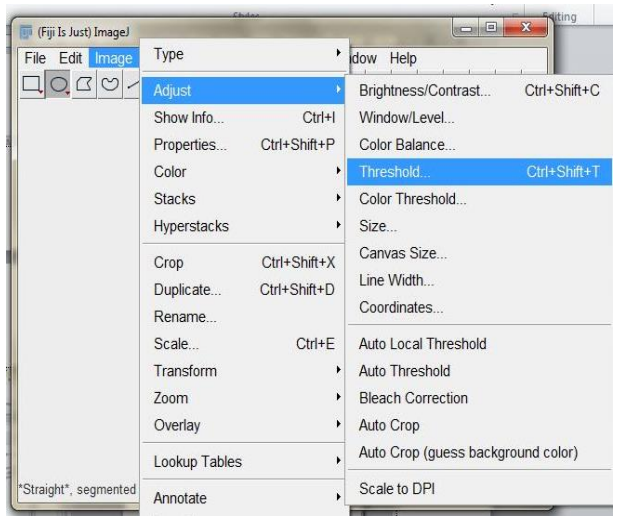

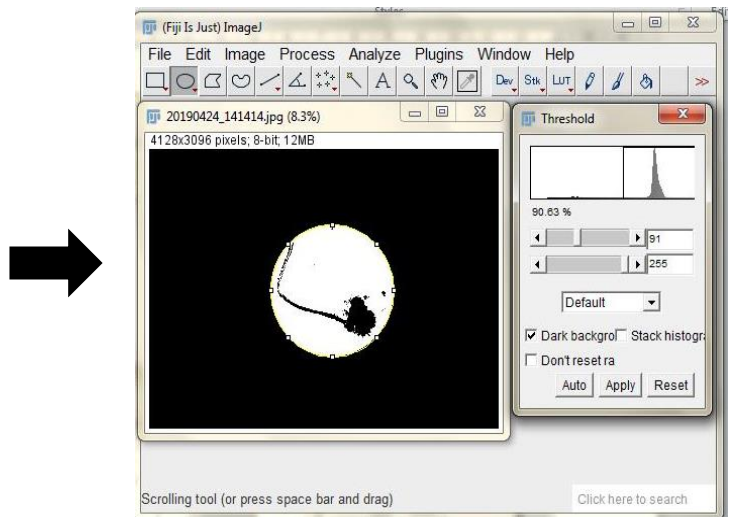


6. Click "Analyze" then select "Set Measurment", then check the description Area, Min \& max gray value, Integrated density and Mean gray.
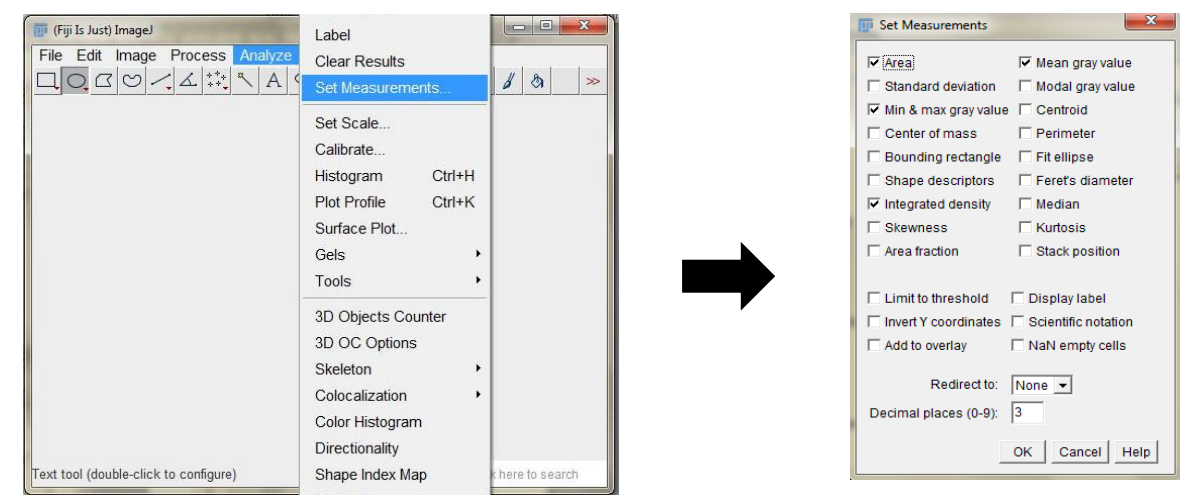

7. After the examination is set, in the "Redirect to" column, the title of the image to be analyzed is selected, then click "OK".
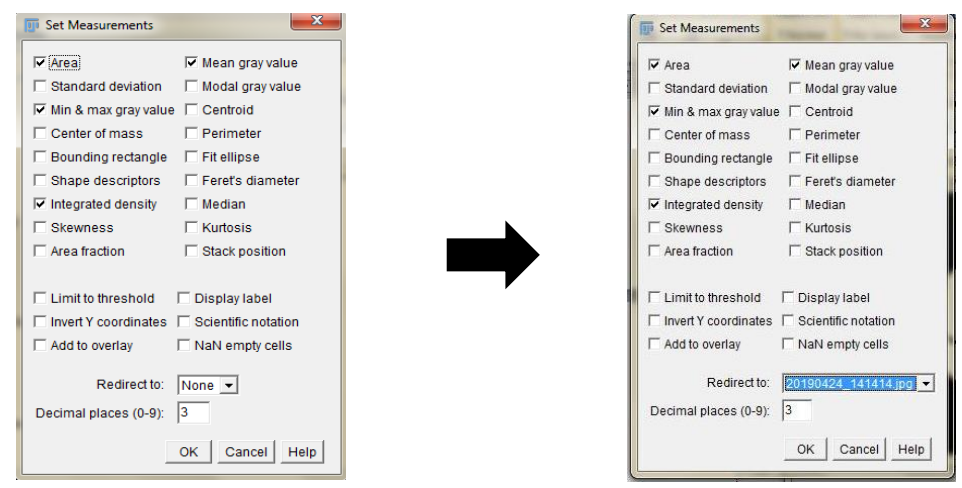

8. Click "Analyze" then select "Measure" or press ctrl $+\mathrm{M}$, after which the results of the analysis that have been done will appear.

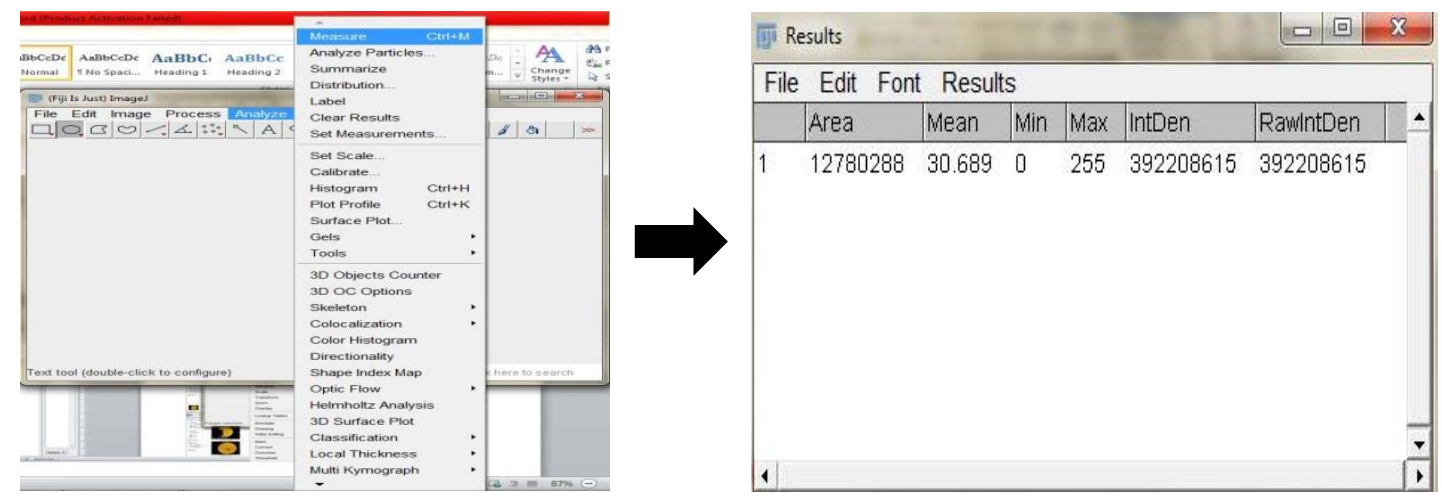




\section{Data analysis}

The data were obtained from microscopic observations of the structure and morphology of fungi and the intensity of the color and then processed the data. Data processing was done descriptively and statistically. Descriptive processing was carried out by observing the binding of the iodine color to the fungal components. Statistical analysis of color intensity data using SPSS v.13 software to obtain the mean value, deviation deviation and ANOVA testing.

\section{RESULT AND DISCUSSION}

Alternative dyes consisted of iodine in various concentrations modified with the addition of $0.25 \%$ lactoglycerol. Each stained sample was made into 9 wet preparations with 5 field of view (Figure 1). Each preparation was observed under a microscope with an objective 40x magnification. The observed of fungal cell wall showed brown color, this is because the fungal cell wall has the main constituent component in the form of chitin. Based on the Van Wesslink reaction, when chitin meets iodine it will produce a brown complex. The Van Wesslink reaction is a test of starch contained in carbohydrates or other organic compounds (Azhar, et al., 2010).

Aspergillus sp. which was stained with iodine glycerol solutions of various concentrations shows the ability of the dye to color the structure and morphology of the fungus. All concentrations used can coloring the structure and morphology of the fungus properly and clearly (Table 1).

The structure and morphology of fungi can be colored because the dye can penetrate into the parts of the fungus through hyphae. The hyphae of the fungus with the septum (bulkhead) has a pore that functions as a place for protoplama to flow throughout the fungus. The vesicle or fungal structure that resembles a sac has a function to bind dyes, this can be caused by vesicles emptying their contents between the protoplasm and the cell wall so that the dye can fill all the gaps in the vesicles (Gandjar, Sjamsuridzal, \& Oetari, 2006).

The addition of lactoglycerol which consists of glycerol and lactic acid in this research functions as a clearing agent in the slide and universal mountant. Glycerol functions as a hygroscopic agent to prevent wet preparations from drying out quickly (Shamly, Kali, Srirangaraj, \& Umadevi, 2014).

\section{The color intensity in the samples stained with iodine lactoglycerol}

The wet preparations of mushrooms were observed microcopically, followed by quantitative testing. The test is done by measuring the color intensity using the image-J program. The data from the measurement of color intensity will then be analyzed descriptively using Statistical Product and Service Solution (SPSS) version 13 software.

From Table 2 Above shows the average value of color intensity on fungi slide increases with increasing concentration of Iodine lactoglycerol. At the lowest concentration of $1.25 \%$ Iodine lactoglycerol, it shows an average value of color intensity is $2.56 \pm 0.78$, and the $2.5 \%$ Iodine lactoglycerol shows an average value of color intensity is $3.06 \pm 0.97$, the highest concentration $5 \%$ Iodine lactoglycerol shows an average value of color intensity is $3.27 \pm 0.15$. The deviation value (SD) shows the uniformity of the value on each test. The lower the SD indicates that the color intensity does not change significantly on each repetition.

The results of the measurement of the mean and deviation deviation are then followed by the ANOVA test after requirements are accepted (normality and homogeneity are accepted with $\mathrm{p}$ value $>0.05)$. The results of the ANOVA test in Table 2. show a significance is $0.380(\mathrm{P}>0.05)$. That value indicates the difference average value of color intensity of the three concentrations tested has no significant difference. 

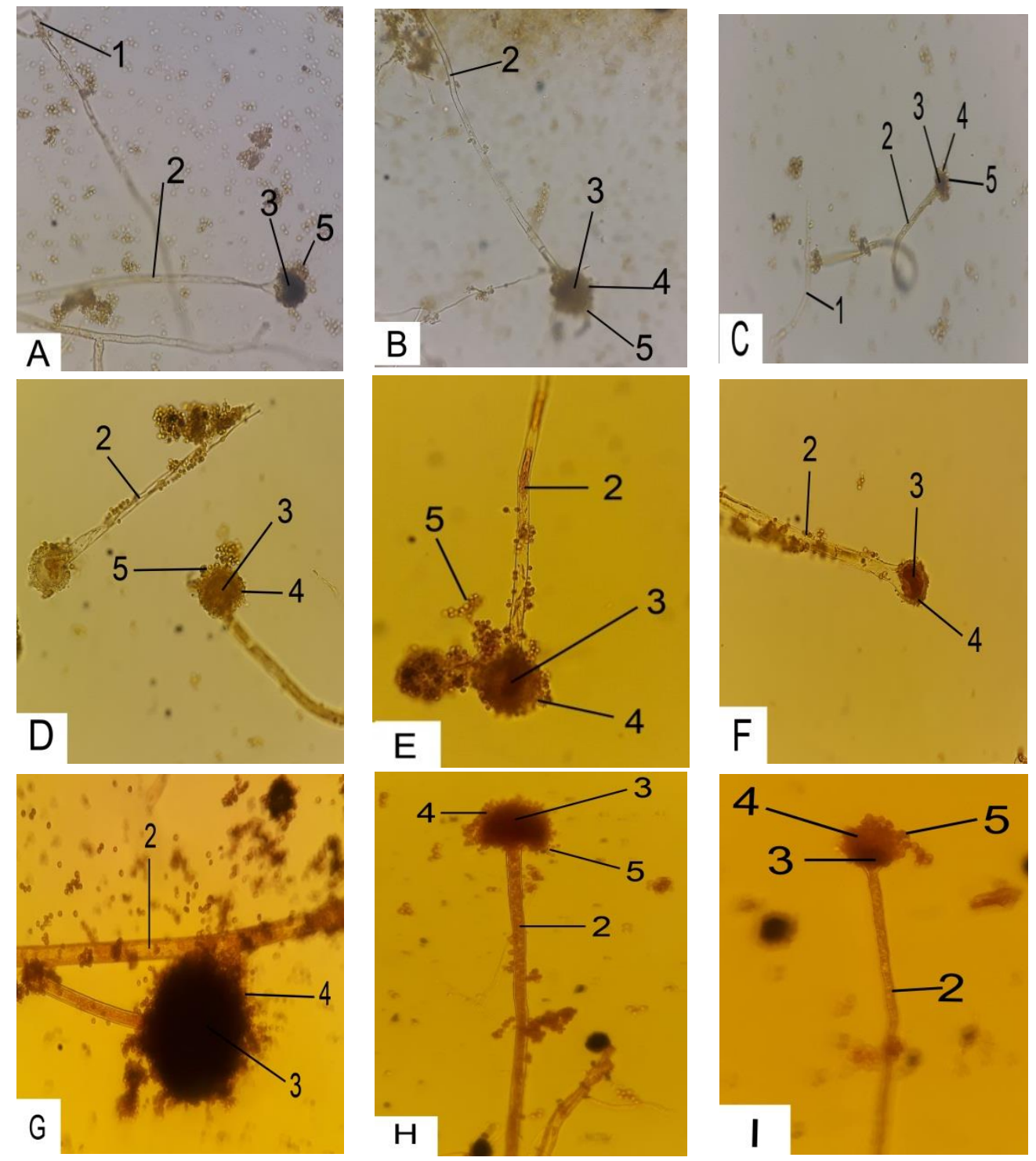

Figure 1: The results of the Microscopic Structure and Morphology of Aspergillus sp. colored by alternative color. Information: Figure $\mathrm{AC}=1.25 \%$ of Iodine lactoglycerol, $\mathrm{DF}=2.5 \%$ of Iodine lactoglycerol, GI $=5 \%$ of Iodine lactoglycerol (Information: $1=$ hyphae, $2=$ conidiophores, $3=$ Vesicles, 4 = Sterigmata, $5=$ Conidiospores)

Table 1. Quality of the Lactoglycerol Iodine Staining to Fungi Structure and Morphology

\begin{tabular}{cccccc}
\hline \multirow{2}{*}{ Concentration (\%) } & \multicolumn{5}{c}{ The results of fungal morphological staining } \\
\cline { 2 - 6 } & Hyphae & Conidiophores & Vesicles & Sterigmata & Conidiospores \\
\hline 1.25 & 1 & 1 & 1 & 1 & 1 \\
2.5 & 1 & 1 & 1 & 1 & 1 \\
5 & 1 & 1 & 1 & 1 & 1 \\
\hline
\end{tabular}

Description: $0=$ Not colored

$1=$ Colored 
The value of color intensity of each concentration measured has a different average. The highest average concentration was $5 \%$ and the lowest was $1.25 \%$. Basava (2016) states that the same proportion of glycerol and iodine can reduce the intensity of the absorbed color, so that lighter colors have a tendency to penetrate better than darker colors. However, the ANOVA test results show that there is no significant difference from the difference in mean. it shows that the difference in concentration does not affect the intensity of the color.

Based on the three concentrations tested, it shows that the concentration of $1.25 \%$ Iodine lactoglycerol is the best concentration among the other two concentrations. This is because the structure and morphology of the fungus can be colored properly and clearly by using the lowest concentration of color solutions. The low color intensity accompanied by descriptive microscopic results showed that the fungus could be colored well without being accompanied by a colored background. The high color intensity shows that Iodine not only colors the mushrooms but also colors the background so that it covers the components of the fungus so that it is difficult or even unnoticed (Basava, 2016).

Table 2. Results of Color Intensity Analysis on Fungi Slide with Various Concentrations of Iodine lactoglycerol

\begin{tabular}{cccccc}
\hline No. & $\begin{array}{c}\text { Concentration } \\
\mathbf{( \% )}\end{array}$ & $\begin{array}{c}\mathbf{X}(\mathbf{x} 105) \pm \mathbf{S D} \\
\mathbf{( x 1 0 2 )}\end{array}$ & $\begin{array}{c}\text { Normality } \\
(\mathbf{p} \text {-value) }\end{array}$ & $\begin{array}{c}\text { Homogeneity } \\
\text { (p-value) }\end{array}$ & $\begin{array}{c}\text { ANOVA } \\
\text { (p-value) }\end{array}$ \\
\hline 1. & 1.25 & $2.56 \pm 0.78$ & 0.347 & & \\
2. & 2.5 & $3.06 \pm 0.97$ & 0.823 & 0.345 & 0.38 \\
3. & 5 & $3.27 \pm 0.15$ & 0.416 & & \\
\hline
\end{tabular}

\section{CONCLUSION}

Alternative Iodine lactoglycerol dye in various concentrations was able to color the structure and morphology of the fungus well and clearly at a concentration of $1.25 \%$. The color intensity value absorbed by Aspergillus sp. which were stained with iodine lactoglycerol in various concentrations did not show any significant difference with a $\mathrm{P}$ value $>0.380$.

\section{REFERENCES}

Adiguna, M. (2001). Epidemiologi dermatomikosis di Indonesia. Dalam p. d. kelamin, Dermatomikosis superficialis. Jakarta: Balai Penerbit Fakultas Kedoteran Universitas Indonesia.

Azhar, M., Efendi, J., Syofyeni, E., Marfa Lesi, R., \& Novalina, D. (2010, Februari). Pengaruh Konsentrasi $\mathrm{NaOH}$ dan $\mathrm{KOH}$ terhadap Derajat Deasetilasi Kitin dari Limbah Kulit Udang. Jurnal EKS AKTA, I.

http://ejournal.unp.ac.id/index.php/jt/index

Basava, S. R., Ambati, S., Jithendra, K., N, P., P., S., \& Mannepuli, C. (2016). Efficacy of Iodine-Glycerol versus. International Journal of Current Microbiology and Applied Sciences, 5(11), 536-541. http:/ /dx.doi.org/10.20546/ijcmas.2016.511.063
IPCS.,2018 Phenol: Health and Safety Guide. Geneva: World Health Organization, 1994. Available at: http://inchem.org/documents/hsg/hsg/hsg88_ e.htm

Gandjar, I., Sjamsuridzal, W., \& Oetari, A. (2006). Mikologi Dasar dan Terapan. Jakarta: Yayasan Obor Indonesia.

Himedia. (2019). Lactophenol Cotton Blue Technical Data. Mumbai: HiMedia Laboratories.

Kazemi, A. (2013). An Overview on the global Frequency of Superficial / Cutaneous Mycoses and Deep Mycoses. Jundishapur J Microbiol, 6(3), 202-204. doi: 10.5812/jjm.10725.

Russel, A. (2003). Simm. Similiarities and differences in the respose of microorganisms to biocides (52:750-63). https://doi.org/10.1093/jac/dkg422

Santana, J.K.G. et al., (2018). Staining Fungal Structures with Artificial Dyes Used in the Industry of Juices. Ciência Rural, 48(9), e20180071. Epub August 06, 2018. https://doi.org/10.1590/0103-8478cr20180071

Shamly, V., Kali, A., Srirangaraj, S., \& Umadevi, S. (2014, July). Comparison of Microscopic Morphology of Fungi Using Lactophenol Cotton Blue (LPCB), Iodine Glycerol and Congo Red Formaldehyde Staining. Journal of Clinical and Diagnostic Research, 8(7), 2.

doi: 10.7860/JCDR/2014/8521.4535

Sujarwani, W. (2015). SPSS untuk penelitian. Yogyakrta: Pustaka Baru Press. 
Tille, P. (2013). Bailey \& Scott's Diagnostic Microbiology (14 ed.). Elsevier.

Vignesh, R. E. (2013). Iodine-glycerol as an alternative to lactophenol cotton blue for identification of fungal elements in clinical laboratory. Indian Journal of medical microbiology, 31(1). doi: 10.4103/0255-0857.108752. 